\title{
Computerized Intervention in Primary Care for Women Veterans with Sexual Assault Histories and Psychosocial Health Risks: a Randomized Clinical Trial
}

\author{
Suzannah K. Creech, Ph.D. ${ }^{1,2}$, Carey S. Pulverman, Ph.D. ${ }^{1,2}$, \\ Christopher W. Kahler, Ph.D. ${ }^{3}$, Lindsay M. Orchowski, Ph.D. ${ }^{4,5}$, M. Tracie Shea, Ph.D. ${ }^{4,6}$, \\ Golfo Tzilos Wernette, Ph.D.?, and Caron Zlotnick, Ph.D. ${ }^{8,9,10}$
}

\begin{abstract}
'VA VISN 17 Center of Excellence for Research on Returning War Veterans and the Central Texas Veterans Health Care System, Waco, TX, USA; ${ }^{2}$ Dell Medical School of the University of Texas at Austin, Austin, TX, USA; ${ }^{3}$ Department of Behavioral and Social Sciences, Brown University School of Public Health, Providence, RI, USA; ${ }^{4}$ Alpert Medical School of Brown University, Providence, RI, USA; ${ }^{5}$ Rhode Island Hospital, Providence, RI, USA; ${ }^{6}$ Providence Veterans Administration Medical Center, Providence, RI, USA; ${ }^{7}$ University of Michigan Medical School, Ann Arbor, MI, USA; ${ }^{8}$ Brown

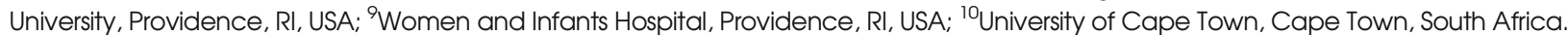

\begin{abstract}
IMPORTANCE: Sexual assault is a public health concern for women and is associated with subsequent psychosocial health risks of posttraumatic stress disorder (PTSD), hazardous drinking, and intimate partner violence (IPV). Sexual assault is associated with social stigma and other barriers shown to inhibit one from seeking mental health care. Digital health technologies may overcome these barriers.

OBJECTIVE: To test the impact of a brief computerized intervention delivered in primary care to reduce health risks and increase mental health treatment utilization among women with histories of sexual assault and current health risks.
\end{abstract}

DESIGN, SETTING, AND PARTICIPANTS: The Safe and Healthy Experiences (SHE) program was tested in a randomized controlled trial with $N=153$ women veterans at a Veterans Health Administration (VHA) medical center, and they completed assessments at baseline, 2 months, and 4 months.

INTERVENTION: $\mathrm{SHE}$ is a brief motivational interviewing and psychoeducation-based computerized intervention. SHE was compared to a screen and referral-only control condition.

MAIN MEASURES: Health risks were measured via validated self-report instruments. Treatment initiation and utilization were measured via self-report and chart review. RESULTS: SHE did not impact women's number of health risks (all $p$ 's > .05). However, women randomized to SHE showed significantly greater increases in treatment use compared to women in the control group, as measured by chart review $\left(\chi^{2}(1, n=153)=4.38, p=.036\right.$, $\left.r_{\mathrm{s}}=.16\right)$, and self-report $\left(\chi^{2}(1, n=130)=5.89, p=.015, r_{\mathrm{s}}\right.$ $=.21)$. SHE was found to be an acceptable intervention. CONCLUSIONS: SHE was effective in improving mental health treatment initiation and utilization compared to a control group. Computer-based interventions to address sexual trauma and its consequences are acceptable, are highly scalable, and can add value to primary care with little cost or increase in provider time.

Received January 28, 2021

Accepted April 22, 2021

Published online May 19, 2021
TRIAL REGISTRATION: Clinicaltrials.gov identifier NCT02957747.

KEY WORDS: sexual assault; women; hazardous drinking; intimate partner violence; posttraumatic stress disorder.

J Gen Intern Med 37(5):1097-107

DOI: $10.1007 / \mathrm{s} 11606-021-06851-0$

(c) This is a U.S. government work and not under copyright protection in the U.S.; foreign copyright protection may apply 2021. This article is an open access publication

S exual assault is highly prevalent among US women af$S$ fecting an estimated $21 \%$ of women in their lifetimes ${ }^{1}$. Lifetime sexual assault is associated with high rates of psychiatric disorders including posttraumatic stress disorder (PTSD) and alcohol use disorder ${ }^{2}$. An unfortunate phenomenon among sexual assault survivors is the repeat experience of gender-based violence including intimate partner violence $(\mathrm{IPV})^{3}$. The experience and consequences of sexual assault and the dual experience of sexual assault and IPV are accompanied by stigma and other barriers shown to delay or inhibit mental health treatment seeking when it is needed, including among women veterans ${ }^{4-8}$. Women veterans experience high rates of sexual assault before, during, and after military service 9,10

Numerous studies have shown the experience of sexual assault is highly stigmatized, and that societal "rape myths" that blame survivors contribute to experiences of stigma, shame, and self-blame that limit treatment seeking ${ }^{8,11}$. These processes have a heightened impact on marginalized populations. For example, sexual, racial, and ethnic minority women experience high rates of sexual assault, are less likely to disclose the assault ${ }^{12,13}$, and are less likely to seek care due to prior experiences of systemic racism and homophobia ${ }^{14}$ compared to other women. These barriers may be enhanced 
among some women veterans seeking care at VA due to the military context in which many assaults occurred, and presence of persons who may remind them of their perpetrator ${ }^{15,16}$, and because racial/ethnic minorities are overrepresented among women veterans compared to the general population ${ }^{17}$. In addition, research has shown that women veterans who identify as sexual minorities are more likely to have experienced childhood or military sexual assault compared to other women veterans ${ }^{18}$.

Digital health technologies offer opportunities to reduce barriers and increase access to mental health care by delivering interventions directly to patients who need them in low- or nostigma settings such as primary care ${ }^{19}$. Digital health technologies can reduce provider barriers including discomfort, lack of time, and lack of support resources ${ }^{20}$ by addressing sexual assault and its consequences outside of the clinical encounter. When implemented within organized healthcare settings, health technologies offer a remedy to fragmented care and lack of care coordination ${ }^{21}$, potentially by screening, briefly intervening, and seamlessly referring patients to needed care. Digital mental health interventions have shown promise in overcoming barriers to care in marginalized populations, but less research has advanced to efficacy testing ${ }^{19}$.

Early work to develop a mobile application to address acute care needs after sexual assault has shown promise ${ }^{22}$; however, we are aware of no other work to address distal mental health care needs after sexual assault. This is an important gap because research shows most women do not volunteer their sexual assault history to providers ${ }^{23}$, many providers do not routinely screen for sexual assault history ${ }^{24}$, and most women will not present to an emergency room or mental health treatment setting in the aftermath of an assault ${ }^{25,26}$, often resulting in delayed or unmet mental health treatment needs. We developed the Safe and Healthy Experiences (SHE) program for women to address barriers to screening for and addressing lifetime sexual assault and related psychosocial health risks of PTSD, hazardous drinking, and IPV ${ }^{27}$. SHE is a modular computer-based screen and brief intervention relying on psychoeducation and the principles of motivational interviewing $(\mathrm{MI})^{28}$ to reduce health risks in women with lifetime sexual trauma histories.

In a prior open trial $(N=20)$, SHE was feasible for use in a Veterans Health Administration (VHA) Women's primary care clinic, and participants reported high satisfaction with the program ${ }^{27}$. The present study is a preliminary randomized controlled trial of SHE compared to a screen and referral-only control condition. Prior work in single session or single session plus booster MI-based interventions has shown these interventions are associated with reductions in hazardous drinking ${ }^{29}$, substance abuse and risky $\operatorname{sex}^{30}$, and degree of $\mathrm{IPV}^{31}$. Single-session telephone intervention has also been associated with better treatment engagement and PTSD symptom reduction compared to a control group ${ }^{32}$. Therefore, it was hypothesized that women who received SHE would evidence reductions in psychosocial health risks (primary outcome) and improved mental health care utilization (secondary outcome) compared to the control group at 2- and 4-month follow-ups. We also examined participant satisfaction with the intervention and the software.

\section{METHOD}

\section{Participants}

Participants were 153 women veterans seeking primary care at a VHA medical center. Inclusion criteria were self-identified female gender, age between 18 and 65, a history of sexual assault (defined as at least one incident of unwanted lifetime sexual contact), and at least one current psychosocial health risk (PTSD, hazardous drinking, and/or IPV). Exclusion criteria were as follows: inability to understand study procedures in English, active suicidal or homicidal crisis warranting imminent clinical intervention. The study was approved by the Institutional Review Board and occurred from May, 2017, through April, 2019. De-identified summary data may be available upon request pending institutional approvals.

\section{Procedure}

Recruitment. The study was advertised via fliers, in-person recruitment in women's primary care clinics, and letters to all women who had primary care appointments scheduled in the next month (see Fig. 1).

Screening Assessment. Interested participants were presented with study details, provided written informed consent, and completed self-report screening measures on an iPad ${ }^{\mathrm{TM}}$ in a private research office. At the conclusion, all participants were provided with a list of mental health and IPV resources within and outside the VA. Eligible women were invited to participate in the randomized controlled trial. Participants were compensated monetarily by gift cards for time spent completing screening (\$10) and assessments $(\$ 30, \$ 40$, and $\$ 50$ for the baseline, 2-month and 4-month follow-ups). All participants screened were also entered into a raffle for $\$ 100$ that was conducted every 100 participants.

Baseline Assessment. Women $(N=153)$ completed a selfreport baseline assessment and were randomized to the intervention or control condition using a standard randomization procedure within the computerized software. After completion of the baseline assessment, the (computer) narrator "flipped a coin" and women $(N=153)$ were randomized into the control or SHE intervention. The randomization sequence was known only to the computer program and optimized for balanced assignment over time between the two conditions. This procedure resulted in $n=76$ assigned to the intervention and $n=$ 77 assigned to the control condition. 


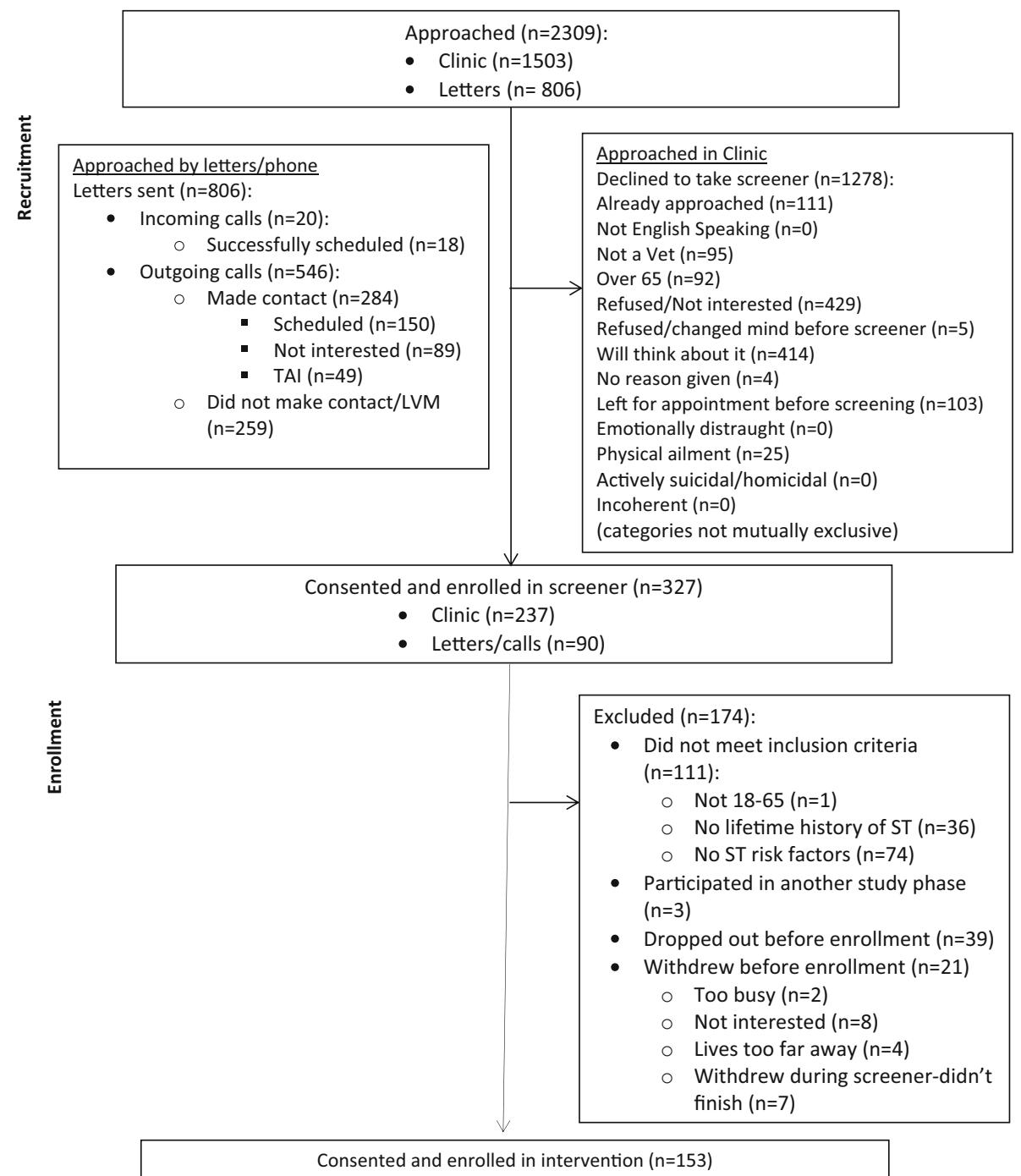

Figure 1 CONSORT table for the randomized controlled trial of the SHE intervention.

Control Procedure. Those randomized to the control condition completed assessments only. After baseline, they were offered a list of mental health and IPV referrals and resources. They were assisted with referrals directly any time throughout the study if requested.

Intervention Procedure. Those randomized to the intervention were presented with the module(s) for each relevant health risk (i.e., PTSD, hazardous drinking, and/or IPV). Modules took about 20 min each and included an audiovisual presentation on the $\mathrm{PPad}^{\mathrm{TM}}$ and corresponding psychoeducational resource handouts. At the conclusion, they were offered a list of mental health and IPV referrals and resources and assisted with referrals directly any time throughout the study if requested.

Intervention Content. SHE was developed using the Computerized Intervention Authoring System (CIAS) ${ }^{33}$. Each SHE intervention module presented personalized feedback from the baseline assessment. Next the modules included psychoeducational information on the health risk endorsed and brief videos of women speaking about that health risk and their own experiences and utilization of resources and/or skills to reduce their risk. Materials were tailored to diverse women who had served in the military. Questions based on motivational interviewing and the stages of change model ${ }^{28}$ were presented. Women reporting high readiness to change (e.g., Yes, I am ready to take steps toward my health) engaged in a goal-setting process using resources from SHE to plan steps toward their goals. Women reporting ambivalence about change (e.g., No, I don't think that I'm ready to take those steps) received targeted feedback, a list of sample pros and cons about change, and information and videos about steps toward change (e.g., building support, self-talk, seeking treatment, evidence based treatment, using resources, safety planning). Modules ended with a motivational video and feedback survey.

Two-Month and Four-Month Follow-Up Assessments. Women completed in-person follow-up assessments on the 


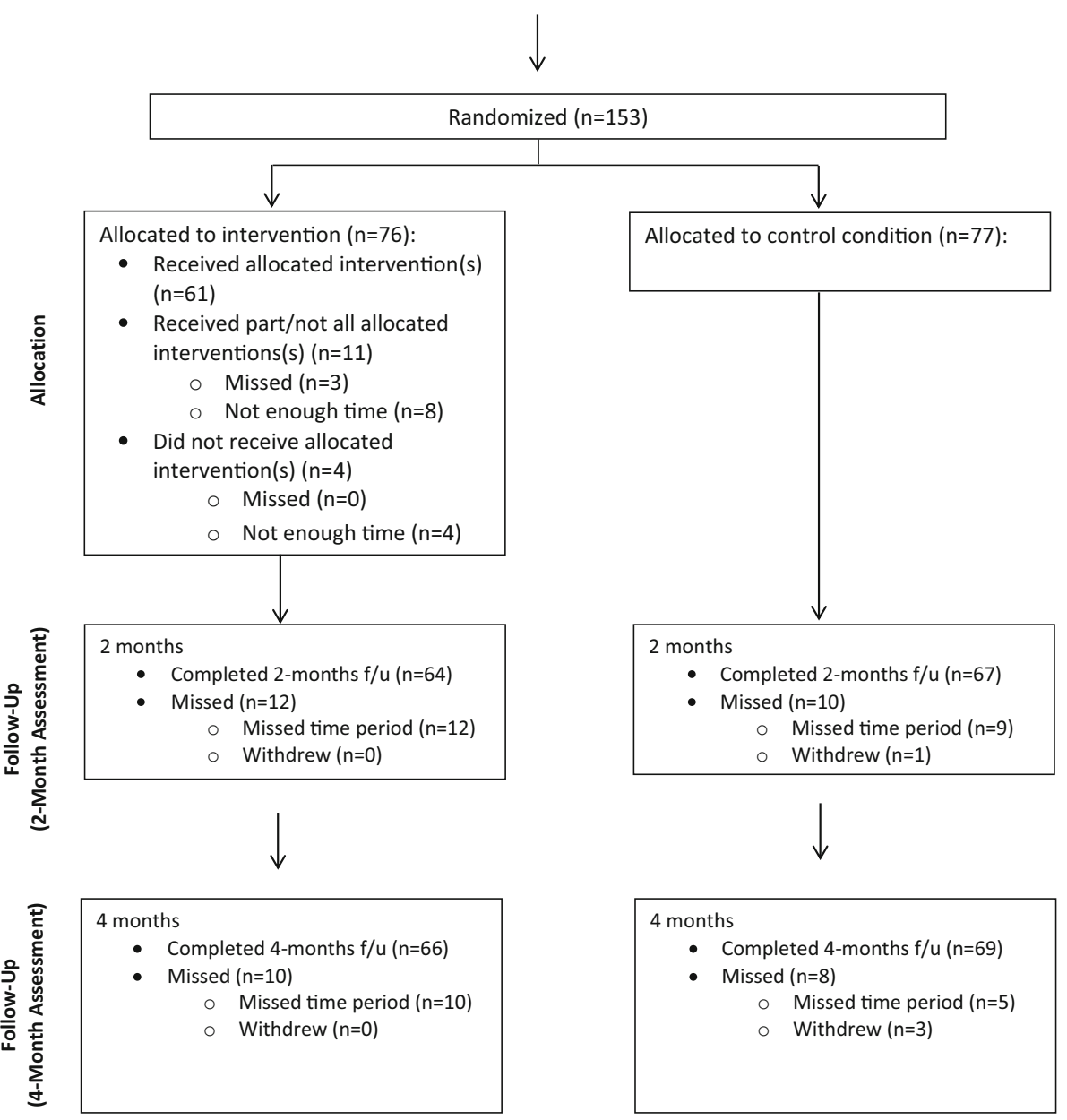

Fig. 1 continued.

$\mathrm{iPad}^{\mathrm{TM}}$ at 2 and 4 months from the date of their baseline assessment. A subset of the sample $(<5 \%)$ completed follow-ups by phone due to moving out of the area or unavailability. All follow-ups were scheduled at the end of the baseline assessment, and women received reminder calls and letters shortly before each follow-up and for any missed follow-ups.

\section{Materials}

Screening Measures. Women completed brief screening measures on history of sexual assault, PTSD, hazardous drinking, and IPV. Experiences of sexual assault were assessed with the Childhood Sexual Victimization Questionnaire (CSVQ) ${ }^{34}$, and the Sexual Experiences Survey-Short Form Victimization (SES-SFV) ${ }^{35}$, and a military sexual assault screener developed by the VHA 36,37. PTSD was assessed with the PTSD Checklist for Diagnostic and Statistical Manual of Mental DisordersFifth Edition (PCL-5) ${ }^{38,39}$. Hazardous drinking was assessed with the Graduated Frequency Measure (GFM) ${ }^{40}$, a measure of alcohol use in the past month and a positive screen was indicted by having four or more drinks on any single day in the past month ${ }^{41,42}$. IPV in the past year was assessed with the Woman Abuse Screening Tool (WAST) ${ }^{43}$. A positive screen for IPV was indexed by a score of four or greater on the WAST.

Baseline, Two-Month, and Four-Month Assessment Measures. Participants completed assessments on PTSD, hazardous drinking, IPV, and treatment utilization at the baseline, 2month, and 4-month assessments. Differences between screening measures and assessment measures are because the screening needed to be completed in approximately $10 \mathrm{~min}$ or less, which required shorter measures for drinking and IPV.

PTSD. Respondents rated past month PTSD symptom severity on the 20 -item PCL- $5^{38,44}$. Higher scores reflect greater symptoms. A score of 33 is the clinical cutoff for probable PTSD and was used as an indicator of PTSD as a health risk ${ }^{39}$. The PCL-5 has excellent psychometric properties $^{39}$. Internal consistency across all administrations in this sample ranged from $\alpha=.95$ to .96 .

Hazardous Drinking. The 10-item Alcohol Use Disorder Identification Test (AUDIT) ${ }^{45}$ was used to assess hazardous drinking as a health risk. At baseline, this was assessed for the 
past year; at follow-ups, this was assessed for the past 2 months. Higher scores reflect greater alcohol use and a score of eight is the cutoff for hazardous drinking ${ }^{46}$. The AUDIT possesses high test-retest reliability and good internal consistency ${ }^{47,48}$. Internal consistency across all administrations in the current sample ranged from $\alpha=.85$ to .88 .

IPV. The Composite Abuse Scale (CAS) is a 30-item measure of IPV in the past 12 months ${ }^{49}$. Higher scores indicate more abuse and a score of 3 or more was used as an indicator that IPV was a health risk. The CAS has evidenced good psychometric properties ${ }^{49}$. Internal consistency across all administrations in the current sample ranged from $\alpha=.91$ to .95 . At follow-ups, participants reported on the past 2 months.

Treatment Use. The Treatment Services Review is a 15item measure of health care treatment use ${ }^{50}$ and was used to assess self-report of mental health treatment in the past 2 months (individual and group therapy, 12-step group sessions, residential substance abuse treatment, psychological testing, inpatient psychiatric care; one day of residential or inpatient psychiatric care was treated as one unit of care). This measure is reported as the total number of mental health care appointments. Study staff also reviewed each participant's medical record and tallied mental health care appointments in the prior 2 months at baseline and follow-ups.

Intervention Feedback. The CIAS Software Scale $\left(\mathrm{SCSS}^{33}\right)$ was used to assess participant satisfaction with the software in terms of likeability, ease of use, interest, and respectfulness. Items are evaluated on a 5-point Likert scale $(1=$ not at all, and $5=$ very much). Internal consistency for the CIAS in the current sample was good $(\alpha=.77)$. Intervention feedback was assessed with the 8-item Client Satisfaction Questionnaire on participant satisfaction with the intervention $\left(\mathrm{CSQ}^{51}\right)$. Internal consistency for the CSQ in the current sample was also excellent $(\alpha=.90)$.

Data Analysis. All analyses use the full intent-to-treat sample. To test our primary hypothesis, we first tested between group effects on the number of health risks present at both 2 months and 4 months using Mantel-Haenszel chi-square tests. We used Spearman rank-order correlations to depict the strength of the association between treatment groups and number of risks. To examine the effect of treatment group over time while controlling for baseline risks, we then ran regression models predicting the number of risks at each follow-up controlling for the number of health risks at baseline. Treatment group was dummy coded with control group as the reference group, and a Poisson distribution with a logit link function was specified for this count outcome.

For treatment utilization during follow-up, the outcome data both from chart review and the TSR were highly positively skewed with some zero inflation. To represent these data in a clinically meaningful way, we categorized each participant's treatment utilization across the 4 months of follow-up into one of the following four levels: no treatment attended; attended treatment up to once a month on average; attended treatment more than once a month on average but not more than weekly; and attended treatment more than weekly. We then used Mantel-Haenszel chi-square tests to determine whether conditions differed significantly at follow-up on these categorical service utilization outcomes with the hypothesis that those receiving SHE would be more likely to be classified as having higher utilization compared to those in control. To depict the strength of the association between treatment group and level of treatment utilization, we calculated Spearman rank-order correlations. We then used logistic regressions to predict utilization level adjusting for the respective value of the outcome at baseline. Ordered logistic regression was used to test whether SHE compared to control was associated with greater odds of being in a higher level of treatment utilization. We also examined satisfaction with the intervention and software as well as intervention effects on raw scores for PCL-5, AUDIT, and CAS.

Sample Size Determination. Sample size was set to detect a medium effect size across primary outcomes with power of .85 using an alpha of .05 . To achieve this power to detect a medium effect size of $w=.30$, a final sample size of 122 was required for a categorical outcome with three levels such as the number of risks. To allow for $20 \%$ loss to follow-up, we set our desired sample size at 150 participants.

\section{RESULTS}

Demographics. Participant ages ranged from 24 to 65 with a mean of $43.55(S D=10.10)$. The sample was diverse, and the majority of participants identified as non-Hispanic and African American/Black or White (see Table 1).

Number of Health Risks (Primary Outcome). Number of health risks at baseline, 2 months, and 4 months are shown in Table 2. At baseline, results of Mantel-Haenszel chi-square tests indicated that the group difference in number of risks was just over the .05 significance level, $\chi^{2}(1, n=152)=2.82, p=$ .09 ; effect size $r_{\mathrm{s}}=.13$, with those in the SHE group reporting a higher number of risks. At 2 months, the linear association between group and number of risks was significant and participants assigned to SHE were more likely to have a higher number of risks, $\chi^{2}(1, n=117)=3.94, p=.047 ; r_{\mathrm{s}}=.20$. This association was nonsignificant at 4 months, $\chi^{2}(1, n=133)=$ $0.97, p=.32 ; r_{\mathrm{s}}=.10$. Results of Poisson regression analyses 
Table 1 Demographics of Study Sample $(N=153)$

\begin{tabular}{|c|c|c|c|c|c|c|}
\hline & \multicolumn{2}{|l|}{ Full sample } & \multicolumn{2}{|l|}{ Control group } & \multicolumn{2}{|c|}{ Intervention group } \\
\hline & $M(\mathrm{SD})$ & Range & $M($ SD) & Range & $M($ SD) & Range \\
\hline Age & $43.55(10.10)$ & $24-65$ & $43.63(10.28)$ & $24-65$ & $43.46(9.97)$ & $26-62$ \\
\hline \multicolumn{7}{|l|}{ Sexual orientation } \\
\hline Heterosexual & 132 & 86.3 & 64 & 83.1 & 68 & 89.5 \\
\hline Bisexual & 7 & 4.6 & 2 & 2.6 & 5 & 6.6 \\
\hline Lesbian & 10 & 6.5 & 7 & 9.1 & 3 & 3.0 \\
\hline Other & 4 & 2.6 & 4 & 5.2 & 0 & 0.0 \\
\hline \multicolumn{7}{|l|}{ Ethnicity } \\
\hline Not Hispanic/Latina & 130 & 85 & 65 & 84.4 & 65 & 85.5 \\
\hline Hispanic/Latina & 23 & 15 & 12 & 15.6 & 11 & 14.5 \\
\hline \multicolumn{7}{|l|}{ Race } \\
\hline African American/Black & 73 & 47.7 & 37 & 48.1 & 36 & 47.4 \\
\hline White & 54 & 35.3 & 26 & 33.8 & 28 & 36.8 \\
\hline Bi-racial/multi-racial & 10 & 6.5 & 8 & 10.4 & 2 & 2.6 \\
\hline Asian & 2 & 1.3 & 0 & 0.0 & 2 & 2.6 \\
\hline Native American or Alaska Native & 2 & 1.3 & 1 & 1.3 & 1 & 1.3 \\
\hline Native Hawaiian or Other Pacific Islander & 1 & .7 & 0 & 0.0 & 1 & 1.3 \\
\hline Other & 9 & 5.9 & 4 & 4.2 & 5 & 6.6 \\
\hline Decline to answer & 2 & 1.3 & 1 & 1.3 & 1 & 1.3 \\
\hline \multicolumn{7}{|l|}{ Education } \\
\hline High school/GED & 12 & 7.8 & 10 & 13.0 & 2 & 2.6 \\
\hline Technical/trade school & 12 & 7.8 & 2 & 2.6 & 10 & 13.2 \\
\hline Some college & 62 & 40.5 & 31 & 40.3 & 31 & 40.8 \\
\hline College graduate & 50 & 32.7 & 24 & 31.2 & 26 & 34.2 \\
\hline Postgraduate & 17 & 11.1 & 10 & 13.0 & 7 & 9.2 \\
\hline \multicolumn{7}{|l|}{ Relationship status } \\
\hline Married & 53 & 34.6 & 27 & 35.1 & 26 & 34.2 \\
\hline Separated & 10 & 6.5 & 6 & 7.8 & 4 & 5.3 \\
\hline Divorced & 54 & 35.3 & 24 & 31.2 & 30 & 39.5 \\
\hline Single, no relationship & 20 & 13.1 & 8 & 10.4 & 12 & 15.8 \\
\hline Single, in a relationship & 16 & 10.5 & 12 & 13.0 & 4 & 5.3 \\
\hline \multicolumn{7}{|l|}{ Sexual trauma history } \\
\hline Unwanted sexual contact childhood & 89 & 58.2 & 46 & 59.7 & 43 & 56.6 \\
\hline Any adulthood sexual assault & 118 & 77.1 & 75 & 97.4 & 76 & 100.0 \\
\hline Adulthood sexual assault & 11 & 7.2 & 8 & 10.4 & 3 & 3.9 \\
\hline Sexual assault during military service & 107 & 69.9 & 54 & 70.1 & 53 & 69.7 \\
\hline
\end{tabular}

adjusting for number of risks at baseline indicated that the effect of intervention condition was nonsignificant at both 2 months (incidence rate ratio $[\mathrm{IRR}]=1.18,95 \% \mathrm{CI}[0.84$, $1.65], p=.34$ ) and 4 months (IRR $=1.07,95 \% \mathrm{CI}[0.77$, $1.51], p=.66)$.
Treatment Use (Secondary Outcome). Table 3 shows the levels of frequency of treatment receipt by chart review and self-report at baseline and across follow-up. Results of MantelHaenszel chi-square tests indicated that at follow-up, the linear association between group and level of treatment engagement was significant, where participants in SHE compared to those

Table 2 Baseline, 2-Month, and 4-Month Health Risks by Treatment Group

\begin{tabular}{|c|c|c|c|c|c|c|c|}
\hline \multirow[t]{2}{*}{$\overline{\text { Time }}$} & \multicolumn{2}{|l|}{$\overline{\text { PTSD }^{\mathrm{a}}}$} & \multicolumn{2}{|c|}{ Hazardous drinking $^{\mathrm{b}}$} & \multicolumn{2}{|l|}{$\overline{\text { IPV }^{\mathrm{e}}}$} & \multirow{2}{*}{$\begin{array}{l}\text { Total } \\
\text { Number of risks } M \\
\text { (SD) }\end{array}$} \\
\hline & $M(\mathrm{SD})$ & $\begin{array}{l}\text { Health risk, } n / N \\
(\%)\end{array}$ & $M$ (SD) & $\begin{array}{l}\text { Health risk, } n / N \\
(\%)\end{array}$ & $M(\mathrm{SD})$ & $\begin{array}{l}\text { Health risk, } n / N \\
(\%)\end{array}$ & \\
\hline \multicolumn{8}{|c|}{ Control group } \\
\hline Baseline & $\begin{array}{l}49.71 \\
(17.44)\end{array}$ & $44 / 77(57.14)$ & $\begin{array}{l}5.83 \\
(5.79)\end{array}$ & $22 / 76(28.94)$ & \multirow{2}{*}{$\begin{array}{l}12.31 \\
(17.34) \\
4.32(8.16)\end{array}$} & $42 / 77(54.54)$ & $1.39(.88)$ \\
\hline 2 months & $\begin{array}{l}35.81 \\
(20.82)\end{array}$ & $32 / 57(56.14)$ & $\begin{array}{l}5.27 \\
(5.60)\end{array}$ & $12 / 59(20.34)$ & & $12 / 59(20.34)$ & $1.05(.93)$ \\
\hline 4 months & $\begin{array}{l}37.52 \\
(20.64)\end{array}$ & $40 / 69(57.97)$ & $\begin{array}{l}4.42 \\
(5.01)\end{array}$ & $14 / 69(20.29)$ & $3.98(8.96)$ & $16 / 68(23.53)$ & $1.00(.81)$ \\
\hline \multicolumn{8}{|c|}{ Intervention group } \\
\hline Baseline & $\begin{array}{l}51.91 \\
(16.95)\end{array}$ & $59 / 76(77.63)$ & $\begin{array}{l}5.55 \\
(5.15)\end{array}$ & $22 / 76(28.94)$ & \multirow{3}{*}{$\begin{array}{l}14.96 \\
(19.92) \\
8.43 \\
(12.79) \\
5.00(9.75)\end{array}$} & $42 / 76(55.26)$ & $1.62(.75)$ \\
\hline$\stackrel{2}{2}$ & $\begin{array}{l}43.58 \\
(18.54)\end{array}$ & $42 / 60(70.0)$ & $\begin{array}{l}4.65 \\
(5.07)\end{array}$ & $15 / 62(24.19)$ & & $28 / 60(46.67)$ & $1.38(.85)$ \\
\hline $\begin{array}{c}4 \\
\text { Months }\end{array}$ & $\begin{array}{l}41.39 \\
(18.07)\end{array}$ & $44 / 65$ (67.69) & $\begin{array}{l}4.52 \\
(5.54)\end{array}$ & $10 / 66(15.15)$ & & $21 / 66(31.81)$ & $1.14(.81)$ \\
\hline
\end{tabular}

${ }^{a}$ PTSD symptoms were assessed with the PTSD Checklist for DSM-5 and the PTSD health risk was defined as a score greater than or equal to 33 ${ }^{b}$ Drinking behavior was assessed with the Alcohol Use Disorder Identification Test (AUDIT) and the hazardous drinking health risk was defined as a score of greater than or equal to eight

${ }^{c} I P V$ was assessed with the Composite Abuse Scale (CAS) and the IPV health risk was defined as a score greater than or equal to three 
Table 3 Treatment Utilization from Baseline to 4-Month Follow-up

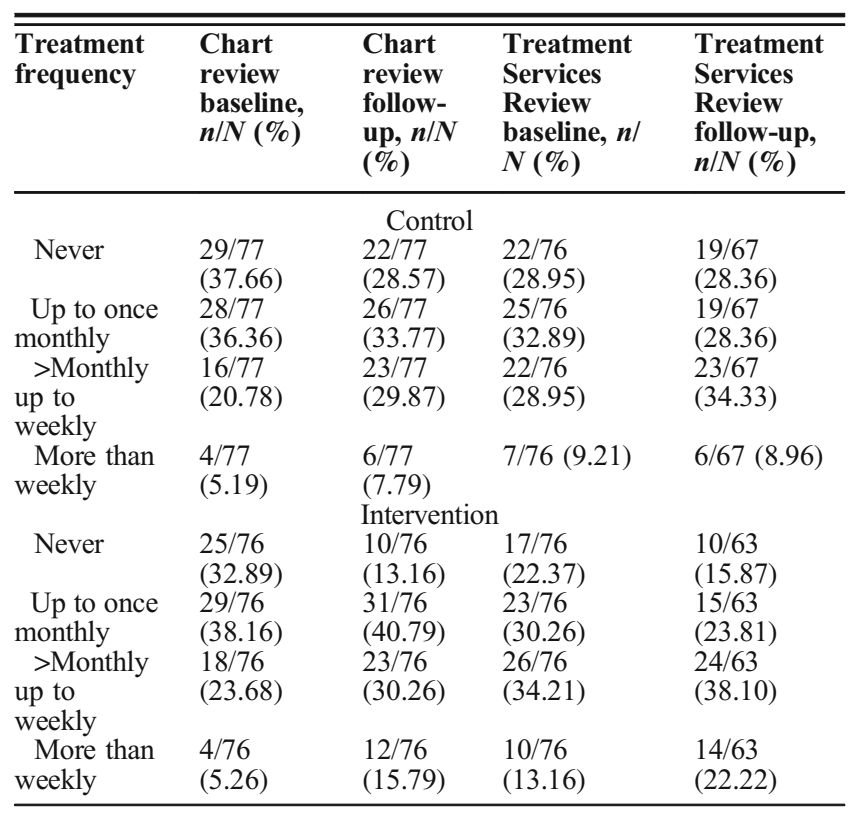

Treatment use was assessed with a chart review of the VHA medical record and via self-report with the Treatment Services Review measure. To represent these data in a clinically meaningful way, we categorized each participant's treatment utilization in each time period into one of the following four levels: no treatment attended; attended treatment up to once a month on average; attended treatment more than once a month on average and but not more than weekly; and attended more than weekly. The baseline time period referred to the two months prior to the baseline appointment. The follow-up time period referred to the four months of follow-up during the study

in control were more likely to have higher levels of treatment as assessed by both chart review $\left(\chi^{2}(1, n=153)=4.38, p=\right.$ $\left..036, r_{\mathrm{s}}=.16\right)$, and self-report $\left(\chi^{2}(1, n=130)=5.89, p=.015\right.$, $\left.r_{\mathrm{s}}=.21\right)$. Differences by group were nonsignificant in the 3 months prior to baseline $\left(\chi^{2}(1, n=153)=0.29, p=.59, r_{\mathrm{s}}=\right.$ .05 , and $\left.\chi^{2}(1, n=152)=1.56, p=.21, r_{\mathrm{s}}=.10\right)$ for chart review and self-report, respectively. Results of ordered logistic regression analyses, which adjusted for baseline, indicated that receiving the SHE intervention compared to control was associated with greater odds of being classified in a higher level of treatment receipt, odds ratio [OR] $=2.17,95 \%$ CI $[1.11,4.24], p=.02$. For level of treatment receipt by self-report, there was a trend toward higher levels of treatment for the intervention group $[\mathrm{OR}]=1.67,95 \%$ CI $[0.92,3.04], p=.09$. Levels of treatment receipt at follow-up are shown in Table 4. The most notable change in the SHE group was among those who did not receive any treatment at baseline, most of whom received at least some treatment during follow-up. This change was much less pronounced in the control group.

Treatment Satisfaction and Change in Raw Scores. Software satisfaction ratings (Table 5) as measured by the SCSS were high $n=95, M=4.42, S D=0.56$, range $=2.86-5$. Treatment satisfaction as measured by the CSQ was moderately high and very similar across each of the modules: PTSD $(n=48, M=$ 3.28 , range $=2.13-4, S D=0.51)$; alcohol use $(n=23, M=$ 3.18 , range $=2.13-4, S D=0.52) ; \mathrm{IPV}(n=31, M=3.35$, range $=2.38-4, S D=0.47$ ).

Means on the PCL-5, AUDIT, or CAS by condition were examined. Results of $t$ tests did not indicate any advantage for the SHE group relative to control at 2 or 4 months on any of these three continuous outcomes with all $p$-values $>.25$ except for the CAS at 2 months. For the CAS at 2 months, those in the SHE cohort reported significantly more interpersonal violence than those in the control, $t(115)=2.06, p=.04$.

\section{DISCUSSION}

The primary goal of this study was to test the impact of a computerized screener and brief intervention delivered in primary care on number of health risks and mental health treatment utilization among women with histories of sexual assault and positive screens for PTSD, hazardous drinking, or IPV. There was no effect of the SHE intervention on number of psychosocial health risks reported during follow-up. However, we found support for our hypothesis that women in the SHE group would evidence improved mental health care utilization compared to the control group. At both 2- and 4-month follow-ups, women in the SHE group had higher rates of treatment initiation and utilization. Findings have important clinical significance for the serious public health concern of sexual assault against women, which is associated with psychiatric disorders ${ }^{2}$, low utilization of mental health treatment ${ }^{4-}$ ${ }^{7}$, and increased risk for re-victimization ${ }^{3}$. The SHE program provides a promising tool for engaging women in mental health treatment that overcomes several provider and patient barriers and has the potential to have a high reach.

Prior research has consistently shown that sexual assault is a highly stigmatized experience and this stigma is a significant contributor to barriers to mental health treatment seeking ${ }^{8}$. Considering the socio-political context in which sexual assault often occurs, it is not surprising most women do not volunteer their sexual assault history to providers ${ }^{23}$, many providers do not routinely screen for sexual assault history ${ }^{24}$, and most women will not present to an emergency room or mental health treatment setting in the aftermath of an assault ${ }^{25,26}$. Sexual, racial, and ethnic minority women experience high rates of sexual assault and are less likely to disclose the assault ${ }^{12,13}$ and to seek care due to prior experiences of systemic racism and homophobia ${ }^{13,14,52}$. Among women veterans who experienced sexual assault in the military, the intersection between gender, race, and sexual identities ${ }^{53}$ may 
Table 4 Relationship Between Treatment Use at Baseline and Treatment Use at Follow-up

\begin{tabular}{|c|c|c|c|c|}
\hline $\begin{array}{l}\text { Treatment frequency } \\
\text { at BL }\end{array}$ & $\begin{array}{l}\text { Follow-up never, } \\
n / N(\%)\end{array}$ & $\begin{array}{l}\text { Follow-up up to once } \\
\text { monthly, } n / N(\%)\end{array}$ & $\begin{array}{l}\text { Follow-up >monthly up to } \\
\text { weekly, } n / N(\%)\end{array}$ & $\begin{array}{l}\text { Follow-up more than } \\
\text { weekly, } n / N(\%)\end{array}$ \\
\hline \multicolumn{5}{|c|}{$\begin{array}{c}\text { Chart review } \\
\text { Control }\end{array}$} \\
\hline BL never & $22 / 29(75.86)$ & $7 / 29(24.14)$ & $0 / 29(0.0)$ & $0 / 29(0.0)$ \\
\hline $\begin{array}{l}\text { BL up to once } \\
\text { monthly }\end{array}$ & $0 / 28(0.0)$ & $17 / 28(60.71)$ & $11 / 28(39.29)$ & $0 / 28(0.0)$ \\
\hline $\begin{array}{l}\text { BL >monthly up to } \\
\text { weekly }\end{array}$ & $0 / 16(0.0)$ & $2 / 16(12.5)$ & $12 / 16(75.0)$ & $2 / 16(12.5)$ \\
\hline $\begin{array}{l}\text { BL more than } \\
\text { weekly }\end{array}$ & $0 / 4(0.0)$ & $0 / 4(0.0)$ & $0 / 4(0.0)$ & $4 / 4(100.0)$ \\
\hline \multicolumn{5}{|c|}{ Intervention } \\
\hline BL never & $10 / 25(40.0)$ & $12 / 25(48.0)$ & $2 / 25(8.0)$ & $1 / 25(4.0)$ \\
\hline $\begin{array}{l}\text { BL up to once } \\
\text { monthly }\end{array}$ & $0 / 29(0.0)$ & $17 / 29(58.62)$ & $10 / 29(34.48)$ & $2 / 29(6.90)$ \\
\hline $\begin{array}{l}\text { BL >monthly up to } \\
\text { weekly }\end{array}$ & $0 / 18(0.0)$ & $2 / 18(11.11)$ & $11 / 18(61.11)$ & $5 / 18(27.78)$ \\
\hline $\begin{array}{l}\text { BL more than } \\
\text { weekly }\end{array}$ & $0 / 4(0.0)$ & $0 / 4(0.0)$ & $0 / 4(0.0)$ & 4/4 (100.0) \\
\hline \multicolumn{5}{|c|}{ Treatment Services Review } \\
\hline BL never & $15 / 18(83.33)$ & $1 / 18$ & $2 / 18(11.11)$ & $0 / 18(0.0)$ \\
\hline $\begin{array}{l}\text { BL up to once } \\
\text { monthly }\end{array}$ & $2 / 21(9.52)$ & $10 / 21(47.62)$ & $9 / 21(42.86)$ & $0 / 21(0.0)$ \\
\hline $\begin{array}{l}\mathrm{BL}>\text { monthly up to } \\
\text { weekly }\end{array}$ & $2 / 21(9.52)$ & $5 / 21(23.81)$ & $11 / 21(52.38)$ & $3 / 21(14.29)$ \\
\hline $\begin{array}{l}\text { BL more than } \\
\text { weekly }\end{array}$ & $0 / 6(0.0)$ & $2 / 6(33.33)$ & $1 / 6(16.67)$ & $3 / 6(50.0)$ \\
\hline \multicolumn{5}{|c|}{ Intervention } \\
\hline $\begin{array}{l}\text { BL never } \\
\text { BL up to once } \\
\text { monthly }\end{array}$ & $\begin{array}{l}5 / 13(38.46) \\
4 / 19(21.05)\end{array}$ & $\begin{array}{l}5 / 13(38.46) \\
6 / 19(31.58)\end{array}$ & $\begin{array}{l}3 / 13(23.08) \\
8 / 19(42.11)\end{array}$ & $\begin{array}{l}0 / 13(0.0) \\
1 / 19(5.26)\end{array}$ \\
\hline $\begin{array}{l}\text { BL >monthly up to } \\
\text { weekly }\end{array}$ & $1 / 22(4.54)$ & 4/22 (18.18) & $10 / 22(45.45)$ & $7 / 22(31.82)$ \\
\hline $\begin{array}{l}\text { BL more than } \\
\text { weekly }\end{array}$ & $0 / 9(0.0)$ & $0 / 9(0.0)$ & $3 / 9(33.33)$ & 6/9 (66.67) \\
\hline
\end{tabular}

Table presents participants' treatment use level (i.e., no treatment attended; attended treatment up to once a month on average; attended treatment more than once a month on average and but not more than weekly; and attended more than weekly) at baseline and at follow-up to illustrate the number of women whose treatment use changed across time. Treatment use included mental health and substance use treatment appointments only. Significantly more women in the intervention group advanced in their treatment use level than women in the control group

contribute to enhanced barriers to care after sexual assault at VA due to institutional reminders of the military context in which many assaults occurred ${ }^{15,16}$. Although further efficacy testing is needed, findings from this study lend support to the growing evidence that digital mental health technologies can overcome barriers to care in marginalized populations ${ }^{19}$.

Other goals of the study were to examine the efficacy of SHE in reducing women's overall number of psychosocial health risks, as well as symptoms of PTSD, hazardous drinking, and recent experiences of IPV compared to the control group. Although other single-session interventions have shown positive effects on drinking, IPV, and PTSD ${ }^{29-32}$, there were no differences in any of these measures between the SHE and control groups, potentially because the study was powered to detect only a medium effect size when most behavioral interventions yield small- to medium-range effect $\operatorname{sizes}^{54}$. Moreover, the study was underpowered to test mediation models, and any impact on clinical outcomes would likely be through treatment utilization. The follow-up period (4 months) was also short in comparison to the time it may take to observe changes in these health risks considering the high levels of symptom severity and comorbidity in the sample. A final confounding factor is the lack of specificity in our measurement of the type of mental health treatment received. For example, women may have sought treatment for a different condition that we did not measure. Patient education on evidence-based treatment for mental health problems has been shown to result in better outcomes ${ }^{55}$, and our lack of measurement of both condition treated and receipt of adequate dose of evidence-based care could have obscured findings. These possibilities should be examined in a future study, with an extended follow-up period and a larger sample size powered to test mediation.

\section{LIMITATIONS}

Limitations of the study include a low sample size to detect small effect sizes or to test mediation models, a low $\mathrm{N}$ in the alcohol group, and a relatively short follow-up period. We also tested SHE with women veterans seeking primary care at the VA, which is an optimal environment to test a computerized intervention to reduce health risks and improve referral to mental health care among women with sexual assault histories but may limit generalizability. Although we pre-specified our 
Table 5 Mean Ratings on Satisfaction with the SHE Intervention

\begin{tabular}{ll}
\hline \hline & $M($ SD) \\
\hline Satisfaction with CIAS Software Scale (SCSS) & \\
How much did you like it? & $4.39(.84)$ \\
How interesting was it? & $4.33(.99)$ \\
Was it easy to use? & $4.84(.45)$ \\
How understandable was it? & $4.82(.46)$ \\
How respectful of you was it? & $4.88(.35)$ \\
How annoyed by it were you?* & 3.52 \\
& $(1.40)$ \\
How interested are you in using the software again in the & 4.14 \\
future? & $(1.06)$ \\
Ratings on the Client Satisfaction Questionnaire (CSQ) & \\
$\quad$ How would you rate the quality of the service you & $3.63(.49)$ \\
received? & $3.41(.54)$ \\
$\quad$ Did you get the kind of services you wanted? & $2.95(.79)$ \\
To what extent has our program met your needs? & $3.41(.54)$ \\
$\quad$ If a friend were in need of similar help, would you & \\
recommend our program? & $3.21(.74)$ \\
$\quad$ How satisfied are you with the amount of help you & \\
received? & \\
$\quad$ Have the services you received helped you to deal more & $3.07(.73)$ \\
effectively with your problems? & \\
$\quad$ In an overall, general sense, how satisfied are you with & $3.26(.69)$ \\
the services you received? & \\
$\quad$ If you were to seek help again, would you come back to & $3.31(.60)$ \\
our program? & \\
\hline
\end{tabular}

${ }^{a}$ The Satisfaction with CIAS Software Scale (SCSS) is rated on a 5-point Likert Scale from $1=$ not at all to $5=$ very much

*This item was reverse scored such that higher scores indicate lower annoyance with the software program

${ }^{b}$ The Client Satisfaction Questionnaire (CSQ) is rated on a 4-point Likert Scale, with higher numbers indicating greater satisfaction. Participants completed these questionnaires after each module; thus, women with multiple risk factors completed these measures in reference to each module respectively. The satisfaction questionnaires were completed a total of 95 times by 72 participants

primary and secondary outcomes, the total number of analyses reported for number of health risks and treatment use (including both chart review and self-report) was large given that we examined health risks at both 2 and 4 months and presented both unadjusted and adjusted treatment effects for all outcomes. Thus, there was some inflation of type I error risk due to this multiple testing. Limitations notwithstanding, strengths of this study include a rigorous, randomized design, and enrollment of a diverse sample of women.

\section{CONCLUSIONS}

To our knowledge, this is the first clinical trial of a modular, computer-based screen, and brief intervention delivered in a primary care setting to address prevalent consequences of sexual assault for women. Although it did not change health risks, SHE was acceptable among women veterans within a primary care setting and improved mental health treatment initiation and utilization compared to a control group. Further study of SHE in a fully powered confirmatory efficacy trial should be conducted. Computer-based interventions to address sexual assault and its consequences appear acceptable, are highly scalable, and can add value to primary care with little increase in provider time. Moreover, computer-based interventions may be uniquely well suited to addressing barriers to care in marginalized populations.

Acknowledgements: The authors wish to acknowledge Dr. Chloe Bird, for her comments on an earlier version of this manuscript, and additional support from the VA Center for the Study of Healthcare Innovation, Implementation \& Policy project ID CIN 13-417. Dr. Creech had full access to all the data in the study and takes responsibility for the integrity of the data and the accuracy of the data analysis

Corresponding Author: Suzannah K. Creech, Ph.D.; VA VISN 17 Center of Excellence for Research on Returning War Veterans and the Central Texas Veterans Health Care System, Waco, TX, USA (e-mail: Suzannah.Creech@va.gov).

Funding This work was supported by a grant from the Department of Defense, W81XWH-14-1-0368. ClinicalTrials.gov identifier: NCT02957747. This work was also supported by additional funds and resources from the VHA VISN 17 Center of Excellence and the Central Texas VA Health Care System.

\section{Declarations:}

Conflict of Interest: Dr. Zlotnick has one conflict of interest to report; her spouse, Dr. Gordon, has served as a physician advisor consultant to a technology company, Soberlink. This company manufactures breathalyzer equipment. Soberlink technology was not used in this study. The authors have no other conflicts of interest to report.

Disclaimer: The views expressed in this article are those of the authors and do not necessarily reflect the position or policy of the Department of Veterans Affairs or the United States government.

Open Access This article is licensed under a Creative Commons Attribution 4.0 International License, which permits use, sharing, adaptation, distribution and reproduction in any medium or format, as long as you give appropriate credit to the original author(s) and the source, provide a link to the Creative Commons licence, and indicate if changes were made. The images or other third party material in this article are included in the article's Creative Commons licence, unless indicated otherwise in a credit line to the material. If material is not included in the article's Creative Commons licence and your intended use is not permitted by statutory regulation or exceeds the permitted use, you will need to obtain permission directly from the copyright holder. To view a copy of this licence, visit http://creativecommons. org/licenses/by/4.0/.

\section{REFERENCES}

1. Smith SG, Zhang $\mathbf{X}$, Basile KC, et al. The National Intimate Partner and Sexual Violence Survey (NISVS): 2015 Data Brief - Updated Release. Published online 2018. Accessed 14 Dec 2020. https://www.cdc.gov/ violenceprevention/pdf/2015data-brief508.pdf

2. Dworkin ER. Risk for Mental Disorders Associated With Sexual Assault: A Meta-Analysis. Trauma Violence Abuse 2020;21(5):1011-1028. https://doi.org/10.1177/1524838018813198

3. Tjaden P, Thoennes N. Extent, Nature, and Consequences of Rape Victimization: Findings From the National Violence Against Women Survey. U.S. Department of Justice; 2006:46. https://www.ncjrs.gov/ pdffiles 1/nij/210346.pdf. Accessed 25 Jan 2021

4. Monteith LL, Bahraini NH, Gerber HR, et al. Military sexual trauma survivors' perceptions of veterans health administration care: A qualitative examination. Psychol Serv 2020;17(2):178-186. https://doi.org/10. $1037 /$ ser0000290

5. Munro ML. Barriers to care for sexual assault survivors of childbearing age: An integrative review. Womens Healthc (Doylestown) 2015;2(4):1929.

6. Murray-Swank NA, Dausch BM, Ehrnstrom C. The mental health status and barriers to seeking care in rural women veterans. J Rural Ment Health 2018;42(2):102-115. https://doi.org/10.1037/ rmh0000095 
7. Altarum Institute. Study of Barriers for Women Veterans to VA Health Care 2015. Womens Health Service of the Department of Veterans Affairs; 2015. Accessed 15 Mar 2021. https://www.womenshealth.va.gov/docs/ WomensHealthServices_BarrierstoCareFinalReport_April2015.pdf

8. Kennedy AC, Prock KA. "I Still Feel Like I Am Not Normal": A Review of the Role of Stigma and Stigmatization Among Female Survivors of Child Sexual Abuse, Sexual Assault, and Intimate Partner Violence. Trauma Violence Abuse 2018;19(5):512-527. https://doi.org/10.1177/ 1524838016673601

9. Morral AR, Gore KL, Schell TL, National Defense Research Institute (U.S.), DoD Sexual Assault Prevention and Response Office (U.S.), eds Sexual Assault and Sexual Harassment in the U.S. Military. Rand Corporation; 2014.

10. Turchik JA, Wilson SM. Sexual assault in the U.S. military: A review of the literature and recommendations for the future. Aggress Violent Behav 2010; 15(4):267-277. https://doi.org/10.1016/j.avb.2010.01.005

11. Edwards KM, Turchik JA, Dardis CM, Reynolds N, Gidycz CA. Rape Myths: History, Individual and Institutional-Level Presence, and Implications for Change. Sex Roles 2011;65(11-12):761-773. https://doi.org/10. 1007/s11199-011-9943-2

12. Slatton BC, Richard AL. Black Women's experiences of sexual assault and disclosure: Insights from the margins. Sociol Compass. 2020;14(6). https://doi.org/10.1111/soc4.12792

13. Tillman S, Bryant-Davis T, Smith K, Marks A. Shattering Silence: Exploring Barriers to Disclosure for African American Sexual Assault Survivors. Trauma Violence Abuse 2010;11(2):59-70. https://doi.org/10. $1177 / 1524838010363717$

14. Bryant-Davis T, Chung H, Tillman S. From the Margins to the Center: Ethnic Minority Women and the Mental Health Effects of Sexual Assault Trauma Violence Abuse 2009;10(4):330-357. https://doi.org/10.1177/ 1524838009339755

15. Turchik JA, Bucossi MM, Kimerling R. Perceived Barriers to Care and Gender Preferences Among Veteran Women Who Experienced Military Sexual Trauma: A Qualitative Analysis. Mil Behav Health 2014;2(2):180188. https://doi.org/10.1080/21635781.2014.892410

16. Gilmore AK, Davis MT, Grubaugh A, et al. "Do you expect me to receive PTSD care in a setting where most of the other patients remind me of the perpetrator?": Home-based telemedicine to address barriers to care unique to military sexual trauma and veterans affairs hospitals. Contemp Clin Trials 2016;48:59-64. https://doi.org/10.1016/j.cct.2016.03.004

17. National Center for Veterans Analysis and Statistics. Profile of Women Veterans: 2015. United States Department of Veterans Affairs; 2016. Accessed 1 Apr 2021. https://www.va.gov/vetdata/docs/SpecialReports/Women_Veterans_Profile_12_22_2016.pdf

18. Mattocks KM, Sadler A, Yano EM, et al. Sexual Victimization, Health Status, and VA Healthcare Utilization Among Lesbian and Bisexual OEF/ OIF Veterans. J Gen Intern Med 2013;28(S2):604-608. https://doi.org/ $10.1007 / \mathrm{s} 11606-013-2357-9$

19. Schueller SM, Hunter JF, Figueroa C, Aguilera A. Use of Digital Mental Health for Marginalized and Underserved Populations. Curr Treat Options Psychiatry 2019;6(3):243-255. https://doi.org/10.1007/ s40501-019-00181-Z

20. Amin P, Buranosky R, Chang JC. Physicians' Perceived Roles, as Well as Barriers, Toward Caring for Women Sex Assault Survivors. Womens Health Issues 2017;27(1):43-49. https://doi.org/10.1016/j.whi.2016.10. 002

21. Bashshur RL, Shannon GW, Krupinski EA, et al. National Telemedicine Initiatives: Essential to Healthcare Reform. Telemed e-Health 2009; 15(6):600-610. https://doi.org/10.1089/tmj.2009.9960

22. Gilmore AK, Davidson TM, Leone RM, et al. Usability Testing of a Mobile Health Intervention to Address Acute Care Needs after Sexual Assault. Int J Environ Res Public Health 2019;16(17):3088. https://doi. org/10.3390/ijerph16173088

23. Littleton HL. The impact of social support and negative disclosure reactions on sexual assault victims: A cross-sectional and longitudinal investigation. J Trauma Dissociation 2010;11(2):210-227. https://doi. org/10.1080/15299730903502946

24. Littleton HL, Berenson AB, Radecki Breitkopf C. An evaluation of health care providers' sexual violence screening practices. Am J Obstet Gynecol. 2007;196(6):564.e1-564.e7. https://doi.org/10.1016/j.ajog. 2007.01.035

25. Resnick HS, Holmes MM, Kilpatrick DG, et al. Predictors of post-rape medical care in a national sample of women1. Am J Prev Med 2000;19(4):214-219. https://doi.org/10.1016/S0749-3797(00)00226-9

26. Wang PS, Lane M, Olfson M, Pincus HA, Wells KB, Kessler RC. TwelveMonth Use of Mental Health Services in the United States: Results From the National Comorbidity Survey Replication. Arch Gen Psychiatry 2005;62(6):629. https://doi.org/10.1001/archpsyc.62.6.629

27. Creech SK, Pulverman CS, Shin ME, et al. An Open Trial to Test Participant Satisfaction With and Feasibility of a Computerized Intervention for Women Veterans With Sexual Trauma Histories Seeking Primary Care Treatment. Violence Against Women. Published online January 3, 2020:107780121989510. https://doi.org/10.1177/1077801219895102

28. DiClemente CC, Prochaska JO. Toward a comprehensive, transtheoretical model of change: Stages of change and addictive behaviors. In: Miller WR, Heather N, eds. Treating Addictive Behaviors., 2nd Ed. Applied clinical psychology. Plenum Press; 1998:3-24. https://doi.org/10.1007/ 978-1-4899-1934-2_1

29. Monti PM, Mastroleo NR, Barnett NP, Colby SM, Kahler CW, Operario D. Brief motivational intervention to reduce alcohol and HIV/sexual risk behavior in emergency department patients: A randomized controlled trial. J Consult Clin Psychol 2016;84(7):580-591. https://doi.org/10. 1037/ccp0000097

30. Wernette GT, Plegue M, Kahler CW, Sen A, Zlotnick C. A Pilot Randomized Controlled Trial of a Computer-Delivered Brief Intervention for Substance Use and Risky Sex During Pregnancy. J Women's Health 2018;27(1):83-92. https://doi.org/10.1089/jwh.2017.6408

31. Zlotnick C, Tzilos Wernette G, Raker CA. A randomized controlled trial of a computer-based brief intervention for victimized perinatal women seeking mental health treatment. Arch Womens Ment Health 2019;22(3):315-325. https://doi.org/10.1007/s00737-018-0895-1

32. Stecker T, McHugo G, Xie $\mathbf{H}$, Whyman $\mathbf{K}$, Jones $\mathbf{M}$. RCT of a Brief Phone-Based CBT Intervention to Improve PTSD Treatment Utilization by Returning Service Members. Psychiatr Serv 2014;65(10):1232-1237. https://doi.org/10.1176/appi.ps.201300433

33. Ondersma S, Chase S, Svikis D, Schuster C. Computer-based brief motivational intervention for perinatal drug use. J Subst Abus Treat 2005;28(4):305-312. https://doi.org/10.1016/j.jsat.2005.02.004

34. Finkelhor $\mathbf{D}$. What's wrong with sex between adults and children? Ethics and the problem of sexual abuse. Am J Orthopsychiatry 1979;49(4):692697. https://doi.org/10.1111/j.1939-0025.1979.tb0265.x

35. Koss MP, Abbey A, Campbell R, et al. Revising the SES: A collaborative process to improve assessment of sexual aggression and victimization. Psychol Women Q 2007;31(4):357-370. https://doi.org/10.1111/j.14716402.2007.00385.x

36. Kimerling R, Gima K, Smith MW, Street A, Frayne S. The Veterans Health Administration and military sexual trauma. Am J Public Health 2007;97(12):2160-2166. https://doi.org/10.2105/AJPH.2006.092999

37. Kimerling R, Street AE, Gima K, Smith MW. Evaluation of universal screening for military-related sexual trauma. Psychiatr Serv 2008;59(6):635-640. https://doi.org/10.1176/appi.ps.59.6.635

38. Weathers FW, Litz BT, Keane TM, Palmieri PA, Marx BP, Schnurr PP. The PTSD Checklist for DSM-5 (PCL-5). Scale available from the National Center for PTSD at www.ptsd.va.gov. Published online 2013.

39. Bovin MJ, Marx BP, Weathers F W., et al. Psychometric properties of the PTSD Checklist for Diagnostic and Statistical Manual of Mental Disorders-Fifth Edition (PCL-5) in Veterans. Psychol Assess 2016;28(11):1379-1391. https://doi.org/10.1037/pas0000254

40. Hilton ME. A comparison of a prospective diary and two summary recall techniques for recording alcohol consumption. $\mathrm{Br} \mathrm{J}$ Addict 1989;84(9): 1085-1092.

41. Dawson DA. U.S. low-risk drinking guidelines: An examination of four alternatives. Alcohol Clin Exp Res 2000;24:1820-1829.

42. National Institute on Alcohol Abuse and Alcoholism. Helping Patients with Alcohol Problems: A Health Practitioner's Guide.; 2003.

43. Brown J, Lent B, Schmidt G, Sas G. Application of the Woman Abuse Screening Tool (WAST) and the WAST-Short in the family practice setting. J Fam Pract 2000;49(10):896-903.

44. Blevins CA, Weathers FW, Davis MT, Witte TK, Domino JL. The posttraumatic stress disorder checklist for DSM-5 (PCL-5): Development and initial psychometric evaluation. J Trauma Stress 2015;28(6):489498. https://doi.org/10.1002/jts.22059

45. Saunders JB, Aasland OG, Babor TF, De la Fuente JR, Grant M. Development of the Alcohol Use Disorders Identification Test (AUDIT): WHO collaborative project on early detection of persons with harmful alcohol consumption-II. Addiction. 1993;88(6):791-804. https://doi.org/ 10.1111/j.1360-0443.1993.tb02093.x

46. Conigrave KM, Hall WD, Saunders JB. The AUDIT questionnaire: Choosing a cut-off score. Addiction. 1995;90(10):1349-1356. https:// doi.org/10.1046/j.1360-0443.1995.901013496.x 
47. Babor TF, Higgins-Biddle JC, Saunders JB, Monteiro MG. AUDIT: The Alcohol Use Disorders Identifications Test: Guidelines for Use in Primary Care. 2nd ed. World Health Organization; 2001.

48. de Meneses-Gaya C, Zuardi AW, Loureiro SR, Crippa JAS. Alcohol Use Disorders Identification Test (AUDIT): An updated systematic review of psychometric properties. Psychol Neurosci 2009;2(1):83-97. https://doi. org/10.3922/j.psns.2009.1.12

49. Hegarty K, Bush R, Sheehan M. The Composite Abuse Scale: Further development and assessment of reliability and validity of a multidimensional partner abuse measure in clinical settings. Violence Vict 2005;20(5):529-547. https://doi.org/10.1891/0886-6708.2005.20.5. 529

50. McLellan AT, Alterman AI, Cacciola J, Metzger D, O'Brien CP. A new measure of substance abuse treatment: Initial studies of the Treatmen Services Review. J Nerv Ment Dis 1992;180(2):101-110. https://doi.org/ 10.1097/00005053-199202000-00007

51. Larsen DL, Attkisson CC, Hargreaves WA, Nguyen TD. Assessment of client/patient satisfaction: Development of a general scale. Eval Program Plann 1979;2(3):197-207. https://doi.org/10.1016/0149-7189(79) 90094-6
52. Starzynski LL, Ullman SE, Townsend SM, Long LM, Long SM. What factors predict women's disclosure of sexual assault to mental health professionals? J Community Psychol 2007;35(5):619-638. https://doi. org/10.1002/jcop.20168

53. Lehavot K, Beckman KL, Chen JA, Simpson TL, Williams EC Race/ethnicity and sexual orientation disparities in mental health, sexism, and social support among women veterans. Psychol Sex Orientat Gend Divers 2019;6(3):347-358. https://doi.org/10.1037/sgd0000333

54. Lindhiem O, Bennett CB, Rosen D, Silk J. Mobile Technology Boosts the Effectiveness of Psychotherapy and Behavioral Interventions: A MetaAnalysis. Behav Modif 2015;39(6):785-804. https://doi.org/10.1177/ 0145445515595198

55. Watts BV, Schnurr PP, Zayed M, Young-Xu Y, Stender P, LlewellynThomas H. A Randomized Controlled Clinical Trial of a Patient Decision Aid for Posttraumatic Stress Disorder. Psychiatr Serv 2015;66(2):149154. https://doi.org/10.1176/appi.ps.201400062

Publisher's Note: Springer Nature remains neutral with regard to jurisdictional claims in published maps and institutional affiliations. 